\title{
Comparison of Canal Transportation and Centering Ability of Rotary I-Race and BT-Race Systems using Cone Beam Computed Tomography: An in vitro Study
}

\author{
${ }^{1}$ Asok Mathew, ${ }^{2}$ Zahraa M Ali, ${ }^{3}$ Ghaya Y Almadhani, ${ }^{4}$ Ahmed Al Radeideh, ${ }^{5}$ Ahmed J Taleb
}

\begin{abstract}
Aim: The aim of the present study was to compare the canal transportation and centering ability of Rotary I-Race and BT-Race systems using cone beam computed tomography (CBCT) in curved root canals $\left(40^{\circ}\right)$ to find better instrumentation technique for maintaining root canal geometry.
\end{abstract}

Materials and methods: Thirty endodontic training blocks, with angle of curvature $40^{\circ}$, were selected into two groups of 15 samples each: BT-Race (group I), I-Race (group II). The blocks were placed in mold made by silicon impression material to facilitate instrumentation and to enable the reproducibility of pre- and postoperative CBCT images.

Preinstrumentation and postinstrumentation images were obtained at three levels, 1,3 , and $5 \mathrm{~mm}$ above the apical foramen and were compared using CBCT software. Amount of transportation and centering ability were assessed. The two groups were statistically compared with one-way analysis of variance (ANOVA).

Results: The mean transportation for group I at 1, 3, and $5 \mathrm{~mm}$ apical was $0.160,0.080$, and $0.046 \mathrm{~mm}$ respectively. The mean transportation for group II at 1,3 , and $5 \mathrm{~mm}$ apical was -0.096 , 0.050 , and $-0.080 \mathrm{~mm}$ respectively. The mean centering ratio for group I at 1,3 , and $5 \mathrm{~mm}$ apical was $0.401,0.481$, and $0.533 \mathrm{~mm}$ respectively. The mean centering ratio for group II at 1,3 , and $5 \mathrm{~mm}$ apical was $0.428,0.540$, and $0.598 \mathrm{~mm}$ respectively.

Conclusion: Under the condition of this study, the two groups showed significant difference and it was found that BT-Race files (group I) have better centering ability and less canal transportation than I-Race (group II).

Clinical significance: The CBCT study will be a more accurate way of estimation of centering ability and canal transportation and hence, will reduce the clinical complications while performing biomechanical preparations.

\footnotetext{
${ }^{1,5}$ College of Dentistry, Ajman University, Fujairah, United Arab Emirates

${ }^{2}$ College of Dentistry, Ajman University, Ajman, United Arab Emirates

${ }^{3}$ College of Dentistry, Ministry of Health, Dubai, United Arab Emirates

${ }^{4}$ College of Dentistry and College of Education, Ajman University Fujairah, United Arab Emirates

Corresponding Author: Asok Mathew, College of Dentistry Ajman University, Fujairah, United Arab Emirates, e-mail: drashokm@gmail.com
}

Keywords: Apical transportation, Centering ability, Cone beam computed tomography, Rotary system.

How to cite this article: Mathew A, Ali ZM, Almadhani GY, Al Radeideh A, Taleb AJ. Comparison of Canal Transportation and Centering Ability of Rotary I-Race and BT-Race Systems using Cone Beam Computed Tomography: An in vitro Study. World J Dent 2018;9(4):297-303.

Source of support: Nil

Conflict of interest: None

\section{INTRODUCTION}

The concept of root canal treatment is to eliminate the necrotic and infected pulpal remnants as well as removing the microorganism involved in pathogenesis. The challenge is to maintain the original outline and the radicular anatomy and hence, to preserve the hard tissues in near original morphology without compromising the complete eradication of microorganism. ${ }^{1}$ High variation in root canal curvature and anatomy can often compromise the outcome of root canal treatment.

Mechanical preparation results in removal of root canal walls, to some extent to remove the biofilm and dentin associated with colonization of microorganisms. However, canal transportation is a procedural error because of removal of more dentin from one side compared with the other side of canal wall, which are located at a similar distance. This error will displace the physiologic end of the canal to a new operator-made location on the external surface of the root, which leads to accumulation of the debris and microorganism. The reason for the poor prognosis in root canal treatment is the inadequate root canal cleaning which will leave some areas left untreated. ${ }^{2}$

However, the development of newer root canal preparation techniques aids to overcome this procedural error, and hence, the original canal shape can be maintained with better centered rotary file system. Moreover, the introduction of these systems in endodontics was an important step to provide easier and faster canal instrumentation and to minimize the procedural errors and operator fatigue. ${ }^{1}$ Moreover, the centering ability can be influenced by both the root canal anatomy and the design of the instrument (taper, flexibility, and type of alloy). ${ }^{3}$

The BT-Race sequence enables practitioners to treat vast majority of canals with different curvatures and anatomy. ${ }^{4}$ 
The features of this system include a color-coded file identification system, three files: BT1 (10/.06), BT2 (35/.00), and BT3 (35/.04), triangular cross-section, available with three lengths 21,25 , and $31 \mathrm{~mm}$, with the recommended speed and torque being $800 \mathrm{rpm}$ and $1.5 \mathrm{Ncm}$ respectively. ${ }^{5}$

The I-Race sequence provides treatment to the majority of cases only with three I-Race NiTi rotary instruments. It enables us easy use and manipulation and is time saving. The features of this system include a color-coded file identification system, three instruments: R1 15/.06, R2 25/.04, and R3 30/.04, available with three lengths 21, 25, and $31 \mathrm{~mm}$, the recommended speed and torque are $600 \mathrm{rpm}$ and $1.5 \mathrm{Ncm}$ respectively. ${ }^{5}$

There are different methodologies to evaluate the apical transportation after biomechanical preparation. In the $\mathrm{CBCT}$, which provides three-dimensional shape of the canals at high resolution, images are highly accurate compared with conventional techniques, with high reducibility and can provide several images from a single canal. ${ }^{6}$

In addition, CBCT is a noninvasive technique that has been utilized to evaluate canal anatomy and shape before and after preparation at different levels. The CBCT scanning is one of the best methods for the assessment of root canal instrumentation techniques. Several methodologies can be used to study the apical transportation and centering ability, but the CBCT is still the most accurate methodology which is being used at the present time. ${ }^{3}$ Considering the advantages of CBCT in the evaluation of canal transportation and centering ability of rotary system, the present study aims to compare the canal transportation and centering ability of BT-Race and I-Race systems using the CBCT technique.

\section{MATERIALS AND METHODS}

This is an in vitro lab study done with 30 endodontic training blocks, FKG Switzerland (high hardness simulated canals made of clear polyester resin), with an angle

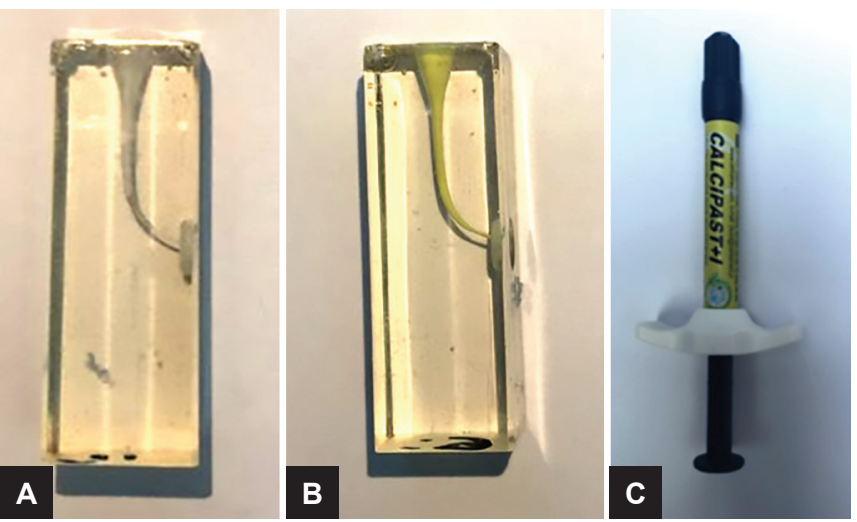

Figs 1A to C: (A) Endodontic block without painting (barium) (B) The endodontic block painted with barium. (C) The intracanal medication for painting

of curvature $40^{\circ}$. They were divided into two groups according to the endodontic instruments used in the canal preparation of 15 samples each: Namely BT-Race (group I) and I-Race (group II). The canals were painted with radio-opaque material Calciplast +1 by Cekamed ${ }^{\circledR}$. Working length was determined by inserting file \#10 $\mathrm{k}$-flex to the canal and reducing $1 \mathrm{~mm}$ from the measurement to preserve the apical constriction (Fig. 1).

The CBCT (Planmeca ${ }^{\circledR}$ Promax 3 d classic , Finland) images were obtained with $90 \mathrm{kV}$ and $6.3 \mathrm{~mA}$ before and after the root canal preparation in three sections $(1,3$, and $5 \mathrm{~mm}$ from apical area) to assess the amount of apical transportation and centering ability (Fig. 2A). The endo blocks were placed in mold made by additional silicon impression material to facilitate instrumentation and to enable the reproducibility of pre- and postoperative CBCT images. All the blocks were instrumented according to manufacturer's guidelines (Fig. 2).

In group I, the root canals were prepared with BT-Race system (FKG DENTAIRE, Switzerland) by using an electric motor (FKG, Rooter, Switzerland) set at a speed of 800 rpm and torque of a $1.5 \mathrm{Ncm}$, with three instruments: BT.1
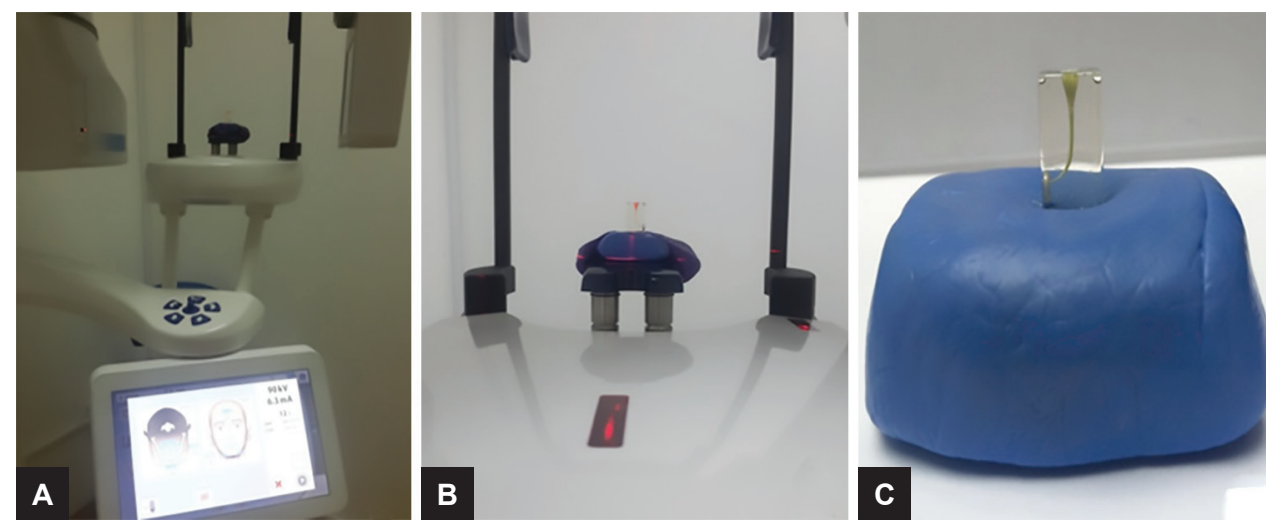

Figs 2A to C: (A) The CBCT machine with the endodontic block. (B) The endodontic block placed in mold made by silicon impression material for CBCT. (C) The endodontic block mould made by silicon impression material for instrumentation 
(10/0.06), BT.2 (35/0.00), and BT.3 (35/0.04) based on the manufacturer's instructions. In group II, all the canals were prepared with I-race system (FKG DENTAIRE, Switzerland) by using three instruments: R1 15/0.06, R2 25/0.04, and R3 30/0.04, and an electric motor (FKG, Rooter, Switzerland) set at a speed of $600 \mathrm{rpm}$ and torque of a $1.5 \mathrm{Ncm}$ based on the manufacturer's instructions. In addition, irrigation was performed in each group with $2 \mathrm{~mL}$ of $5.25 \% \mathrm{NaOCl}$ during the instrumentation and 1 $\mathrm{mL}$ of $17 \%$ ethylene diamine tetraacetic acid for 1 minute, followed by a final flush with $5 \mathrm{~mL}$ of $\mathrm{NaOCl}$.

All the instruments in groups I and II were discarded after use in four canals or as and when any defect or deformation was observed in the shape or structure of the file. The operator prepared only six canals each day so that a constant and uniform force would be applied during canal preparation and operator fatigue would not have any effect on the results. Postoperative CBCT images were obtained after biomechanical preparation to allow us to calculate canal transportation and centering ability.

\section{Evaluation of Canal Transportation}

The determination was done by measuring the distance from the edge of unprepared canal to the periphery of the mesial and distal root, and this had to be compared with the similar measurement obtained from the prepared images. These values were measured by two observers to avoid bias and the mean value was taken.

a1 is the smallest distance from the mesial edge of the root to the mesial edge of unprepared canal.

$\mathrm{b} 1$ is the smallest distance from the distal edge of the root to the distal edge of unprepared canal.

$\mathrm{a} 2$ is the smallest distance from the mesial edge of the root to the mesial edge of a prepared canal.

b2 is the smallest distance from the distal edge of the root to the distal edge of a prepared canal.

The formula (a1-a2) - (b1-b2) is to be used to calculate the apical transportation. According to the formula if it

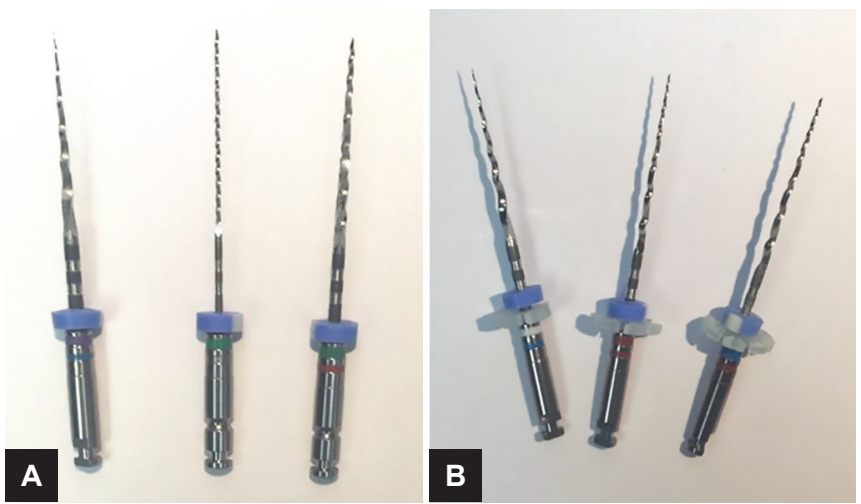

Figs 3A and B: (A) BT-Race files. (B) I-Race files

is equal to zero, it means lack of transportation; positive value indicates the direction of transportation toward the mesial, while negative value the direction toward the distal side (Figs 3 to 7).

Descriptive statistics and one-way ANOVA was done to get the significant difference in the mean degree of transportation of canal between the two shaping procedures. The level of significance was set at $p=0.05$.

\section{Evaluation of Centering Ability}

The centering ability was calculated for each section by applying the following ratio: $\{\mathrm{b} 1-\mathrm{b} 2\} /\{\mathrm{a} 1-\mathrm{a} 2\}$ or $\{\mathrm{a} 1-\mathrm{a} 2\} /$ $\{b 1-b 2\}$. The mean transportation for group I at 1, 3, and $5 \mathrm{~mm}$ apical was $0.160,0.080$, and $0.046 \mathrm{~mm}$ respectively. The mean transportation for group II at 1, 3, and $5 \mathrm{~mm}$ apical was $-0.096,0.050$, and $-0.080 \mathrm{~mm}$ respectively (Tables 1 and 2).

\section{Centering Ability}

The mean centering ratio for group I at 1,3 , and $5 \mathrm{~mm}$ apical was $0.401,0.481$, and $0.533 \mathrm{~mm}$ respectively. The mean centering ratio for group II at 1,3 , and $5 \mathrm{~mm}$ apical was $0.428,0.540$, and $0.598 \mathrm{~mm}$, respectively (Table 3 ).

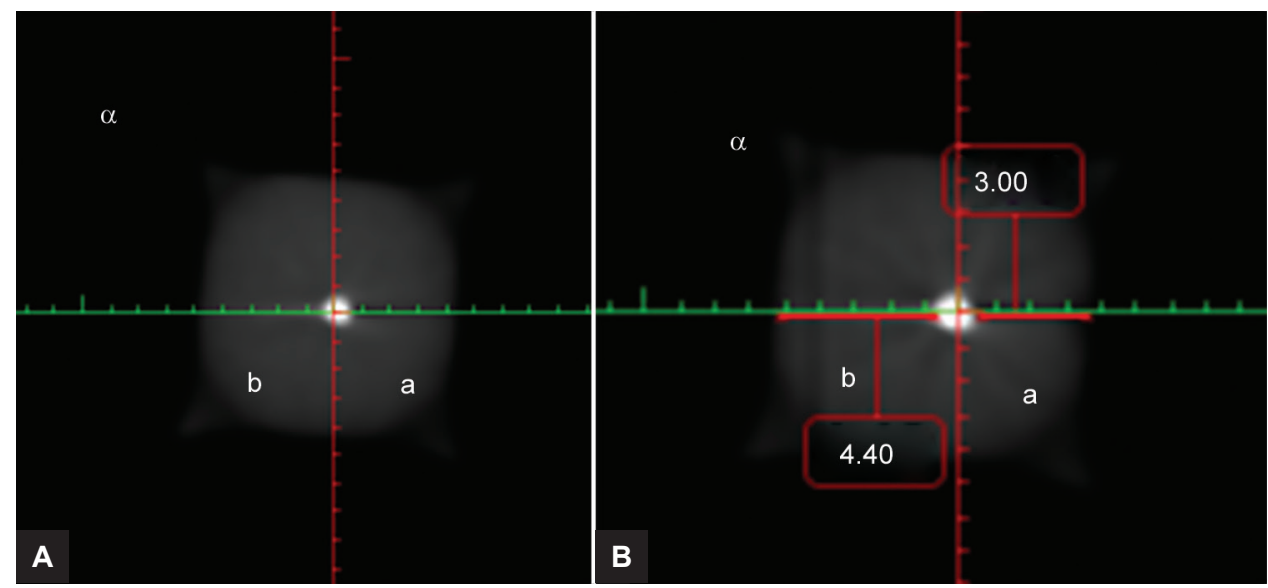

Figs 4A and B: (A) BT-Race (1 mm), before preparation. (B) BT-Race (1 mm), after preparation 


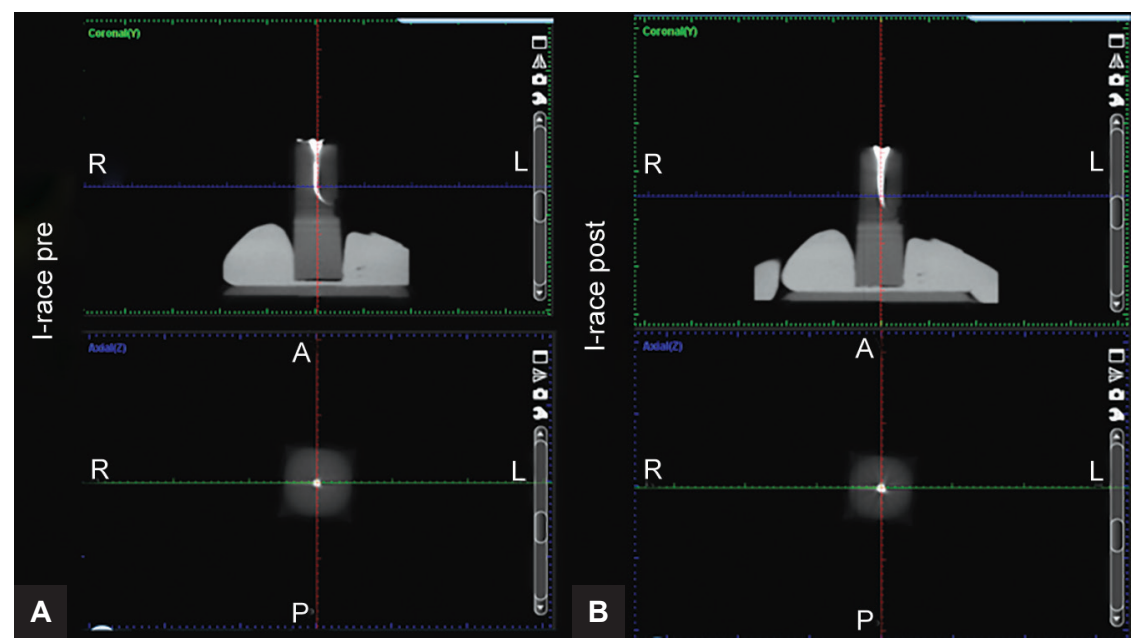

Figs $5 \mathrm{~A}$ and $\mathrm{B}$ : The CBCT image for I-Race before and after preparation

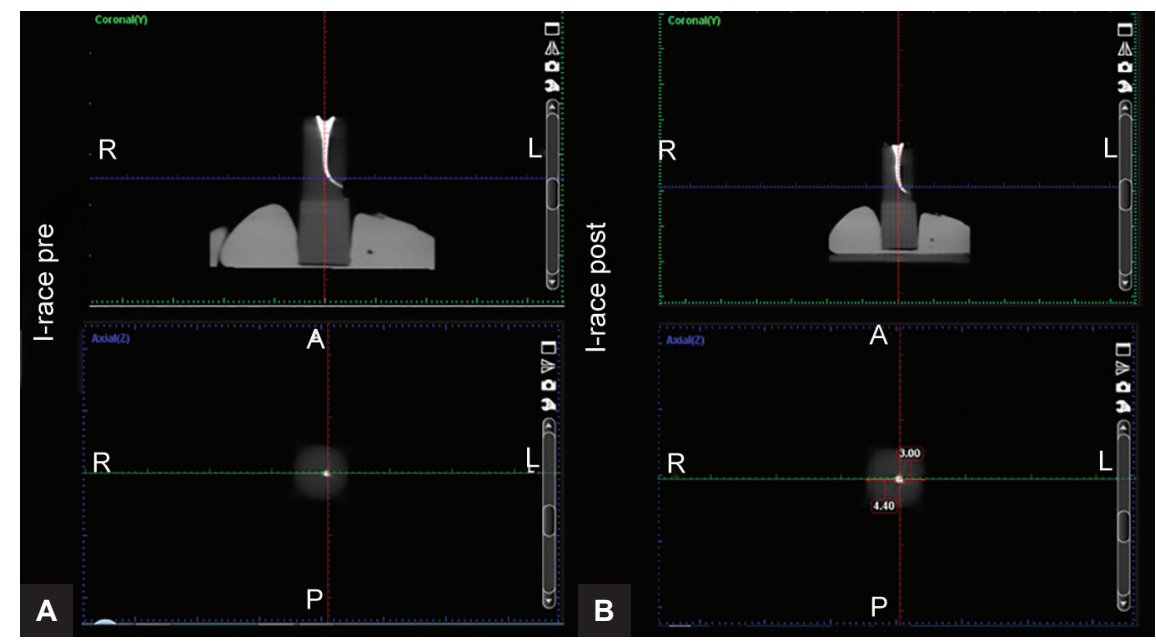

Figs $6 \mathrm{~A}$ and $\mathrm{B}$ : The $\mathrm{CBCT}$ image for $\mathrm{BT}$-Race before and after preparation

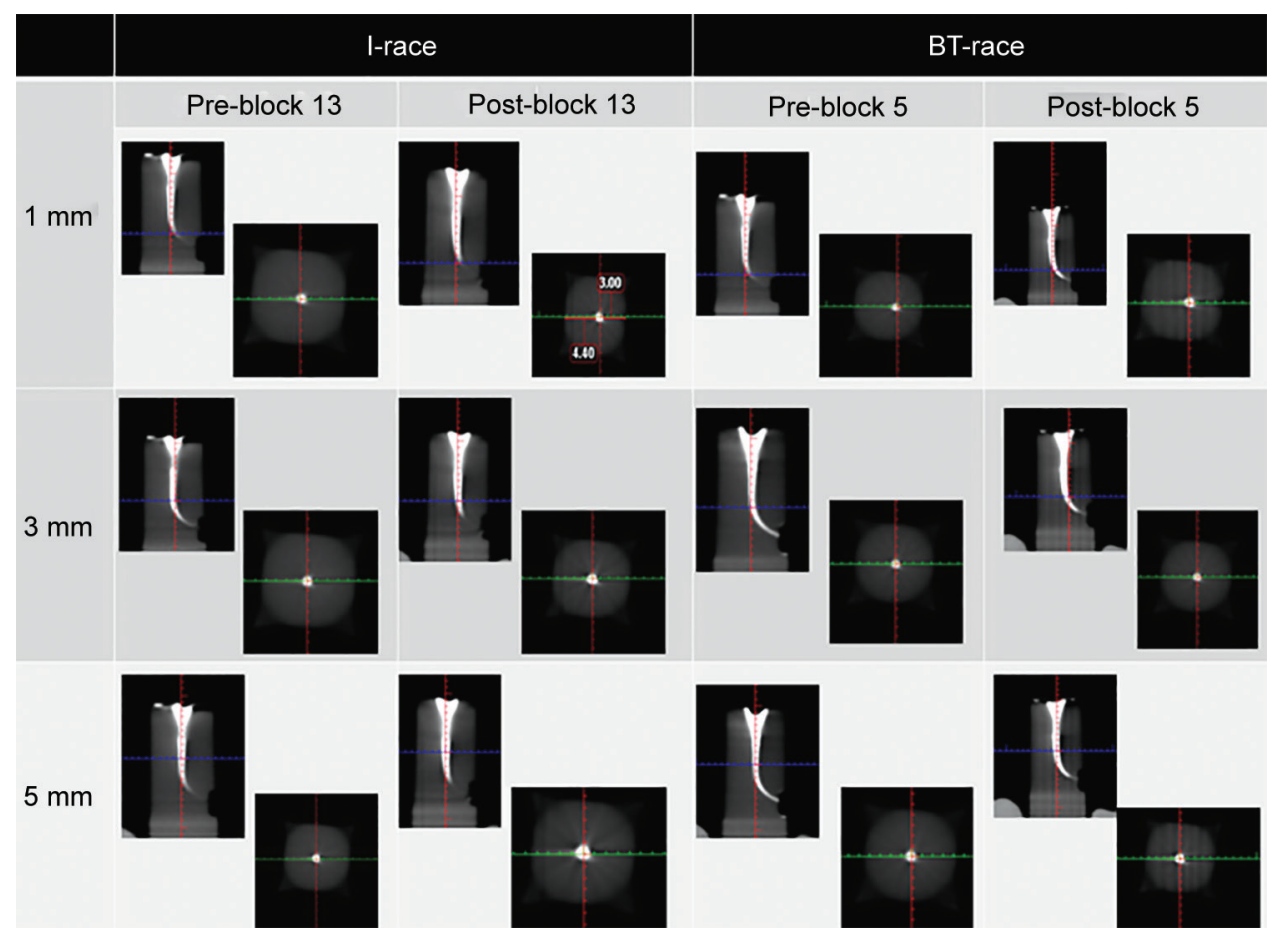

Fig. 7: Postoperative СВСТ images 
Comparison of Canal Transportation and Centering Ability of Rotary I-Race

Table 1: Distribution of mean and SD values of apical transportation at 1,3 , and $5 \mathrm{~mm}$ apical in groups I and II

\begin{tabular}{lllrll}
\hline \multicolumn{2}{l}{ Apical transportation } & $n$ & \multicolumn{1}{c}{ Mean } & SD & $\begin{array}{l}\text { Std. error } \\
\text { mean }\end{array}$ \\
\hline $1 \mathrm{~mm}$ & BT & 15 & 0.1300 & 0.25995 & 0.06712 \\
& I-Race & 15 & -0.0967 & 0.32921 & 0.08500 \\
$3 \mathrm{~mm}$ & BT & 15 & 0.0800 & 0.14976 & 0.03867 \\
& I-Race & 15 & 0.0500 & 0.26592 & 0.06866 \\
$5 \mathrm{~mm}$ & BT & 15 & 0.0467 & 0.09722 & 0.02510 \\
& I-Race & 15 & -0.0800 & 0.20857 & 0.05385 \\
\hline
\end{tabular}

SD: Standard deviation

Table 3: Distribution of mean and SD values of centering ability at 1,3 , and $5 \mathrm{~mm}$ apical in groups I and II

\begin{tabular}{llllll}
\hline Centering ability & $n$ & Mean & SD & $\begin{array}{l}\text { Std. error } \\
\text { mean }\end{array}$ \\
\hline $1 \mathrm{~mm}$ & BT & 15 & 0.4013 & 0.38502 & 0.09941 \\
& I-Race & 15 & 0.4280 & 0.50189 & 0.12959 \\
$3 \mathrm{~mm}$ & BT & 15 & 0.4813 & 0.35098 & 0.09062 \\
& I-Race & 15 & 0.5400 & 0.52218 & 0.13483 \\
$5 \mathrm{~mm}$ & BT & 15 & 0.5333 & 0.21927 & 0.05662 \\
& I-Race & 15 & 0.5980 & 0.59359 & 0.15326 \\
\hline
\end{tabular}

SD: Standard deviation

\section{Analysis of Variance}

The perfect centering equals value of 1 . The level of significance $(p=0.05)$ was set for the one-way ANOVA to
Table 2: Distribution of mean and SD values of apical transportation at 1,3 , and $5 \mathrm{~mm}$ apical in groups I and II

\begin{tabular}{llllll}
\hline \multicolumn{2}{l}{ Apical transportation } & $n$ & \multicolumn{1}{c}{ Mean } & \multicolumn{1}{l}{$S D$} & $\begin{array}{l}\text { Std. error } \\
\text { mean }\end{array}$ \\
\hline $1 \mathrm{~mm}$ & BT & 15 & 0.1300 & 0.25995 & 0.06712 \\
& I-Race & 15 & -0.0967 & 0.32921 & 0.08500 \\
$3 \mathrm{~mm}$ & BT & 15 & 0.0800 & 0.14976 & 0.03867 \\
& I-Race & 15 & 0.0500 & 0.26592 & 0.06866 \\
$5 \mathrm{~mm}$ & BT & 15 & 0.0467 & 0.09722 & 0.02510 \\
& I-Race & 15 & -0.0800 & 0.20857 & 0.05385 \\
\hline
\end{tabular}

SD: Standard deviation

test the significant difference in the mean centering ratio between the two shaping procedures. In the ANOVA table, the p-value (0.025) for $1 \mathrm{~mm}$ and (0.042) for $5 \mathrm{~mm}$ indicates that there is sufficient evidence that not all the means are equal when alpha is set at 0.05 . While in $3 \mathrm{~mm}$, the $p$-value (0.706) indicates that there is no evidence that not all the means are equal (Table 4).

\section{Direction of Apical Transportation}

The direction of apical transportation in BT-Race was toward the mesial side while the direction of apical transportation in I-Race was toward the distal side. Moreover, most number of blocks with no deviation was found with the BT-Race system (Graphs 1 and 2).

Table 4: One-way ANOVA: BT vs I-Race for each group (1, 3, and $5 \mathrm{~mm}$ )

\begin{tabular}{|c|c|c|c|c|c|c|}
\hline \multicolumn{7}{|c|}{ ANOVA } \\
\hline & & Sum of squares & $d f$ & Mean square & $F$ & Sig. \\
\hline \multirow[t]{3}{*}{$1 \mathrm{~mm}$} & Between groups & 0.494 & 1 & 0.494 & 5.616 & 0.025 \\
\hline & Within groups & 2.463 & 28 & 0.088 & & \\
\hline & Total & 2.957 & 29 & & & \\
\hline \multirow[t]{3}{*}{$3 \mathrm{~mm}$} & Between groups & 0.007 & 1 & 0.007 & 0.145 & 0.706 \\
\hline & Within groups & 1.304 & 28 & 0.047 & & \\
\hline & Total & 1.311 & 29 & & & \\
\hline \multirow[t]{3}{*}{$5 \mathrm{~mm}$} & Between groups & 0.120 & 1 & 0.120 & 4.545 & 0.042 \\
\hline & Within groups & 0.741 & 28 & 0.026 & & \\
\hline & Total & 0.862 & 29 & & & \\
\hline
\end{tabular}

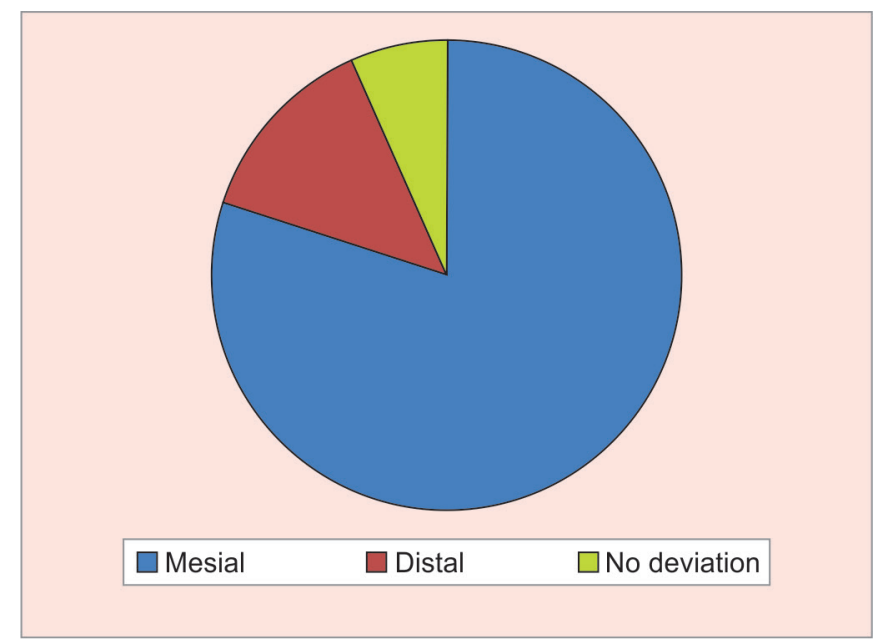

Graph 1: Direction of apical transportation with BT Race

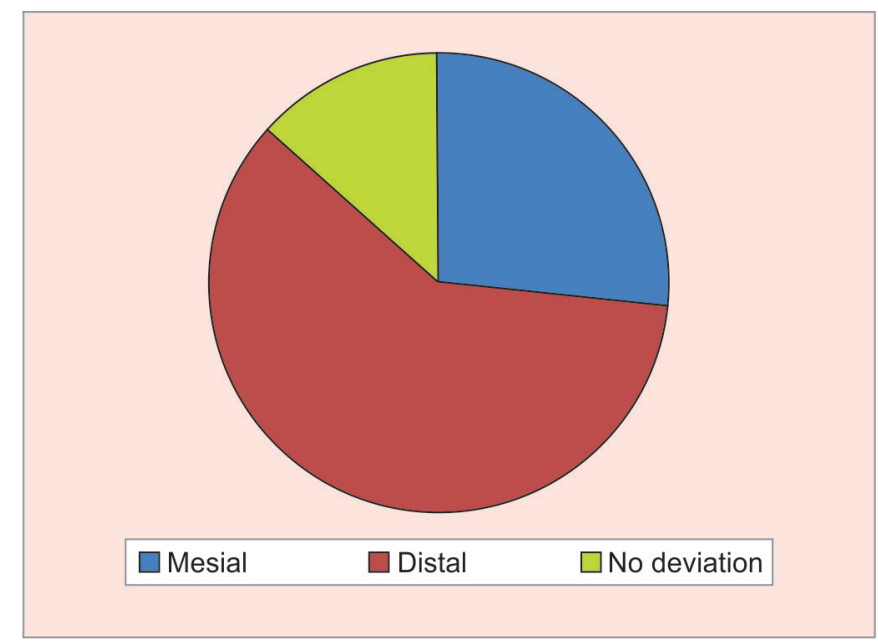

Graph 2: Direction of apical transportation with I- Race 


\section{DISCUSSION}

Apical transportation is defined as excessive removal of the dentin from one direction rather than other direction. It can lead to unequal dentin removal as well as high risk of forming ledges and straightening the original canal curvature. $^{\text {? }}$

Apical transportation results in inadequate cleaning of the root canal, poor sealing efficiency with a high rate of debris extrusion and postoperative discomfort, which may adversely affect the prognosis of the treatment. ${ }^{8,9}$ In a study by Khalilak et $\mathrm{al}_{1}^{10}$ they compared the apical transportation between the extracted teeth and simulated resin blocks. The high hardness simulated resin blocks and extracted teeth displayed similar apical transportation while the low hardness resin blocks showed more apical transportation than high hardness resin blocks as well as extracted teeth.

This study evaluates the transportation of the canal and centering ability by using two different systems, which are BT-Race and I-Race systems. There is significant variation between the two rotary systems used in the study for canal transportation and centering ability. There are studies suggesting that by increasing the diameter of the files, the tendency of the canal transportation is increased. ${ }^{7}$

Hence, greater taper endodontic instruments of more than 0.006 is not preferred for enlargement of apical area, especially for carved canal. The acceptable apical transportation is up to $0.015 \mathrm{~mm}$ and should not be above $0.30 \mathrm{~mm}$ at the apical end. In this study, the two groups showed canal transportation of 0.04 to $0.13 \mathrm{~mm}$, which is within the acceptable range. I-Race and BT-Race files both have a non-screw design and triangular cross-section in which the flexibility and cutting efficiency are increased. Moreover, the electro-polished design aids in decreasing torsional and cyclic fatigue, which could explain its resistance to fracture. ${ }^{7}$

Previous studies showed that a lesser amount of transportation takes place with files that are more flexible. It is found that the centered canal preparation mostly depends on the flexibility, its design, and instrumentation techniques. In this study's results, the amount of canal transportations was generally small with better a centering ability for the BT-Race system. The reason for the small amount of transportation induced by BT-Race is explained by the file flexibility. The file sequences and specialized tip of the BT-Race instrument allow adequate apical preparation sizes, and it ensures that the original canal shape is maintained. It allows keeping the files centered in the canal. In addition to that, the key feature of the BT files is its tip which allows following the curvature of the canals with limited stress on file or the root. Moreover, it has six cutting edges at the tip, for increased cutting efficiency. These are the reasons for small amount of observed transportation. ${ }^{11,12}$ Moreover, the recommended speed is $800 \mathrm{rpm}$ for the BT-Race, which will reduce the risk of breakage. By using the rotary system with NiTi files, it presents an adequate technology for instrumentation of canals and to prepare the apical area with lower rate of deviation compared with manual instrument. ${ }^{12}$

Regarding CBCT image analysis, the advantages include images which are geometrically precise, with canal being assessed with coronal, sagittal, and axial sections with slices of $0.25 \mathrm{~mm}$ thickness will increase the sensitivity and specificity. ${ }^{13,14}$

\section{CONCLUSION}

Within the limitations of this study, the two groups showed significant difference and it was found that BT-Race files (group I) has better centering ability and less canal transportation than I-Race (group II). The direction of apical transportation in BT-Race was toward the mesial side while the direction of apical transportation in I-Race was toward the distal side. Moreover, the most number of blocks with no deviation was also found in BT-Race system.

\section{ACKNOWLEDGMENT}

The authors sincerely thank the radiology technician Mr Michel Clarito, Ajman University for his timely help in carrying out this research.

\section{REFERENCES}

1. Naseri M, Paymanpour P, Kangarloo A, Haddadpur S, Dianat $\mathrm{O}$, Ketabi MA. Influence of motion pattern on apical transportation and centering ability of WaveOne single-file technique in curved root canals. Dent Res J (Isfahan) 2016 Jan-Feb;13(1):13-17.

2. Madani ZS, Haddadi A, Haghanifar S, Bijani A. Cone-beam computed tomography for evaluation of apical transportation in root canals prepared by two rotary systems. Iran Endod J 2014 Spring;9(2):109-112.

3. Tambe VH, Nagmode PS, Abraham S, Patait M, Lahoti PV, Jaju N. Comparison of canal transportation and centering ability of rotary protaper, one shape system and wave one system using cone beam computed tomography: an in vitro study. J Conserv Dent 2014 Nov;17(6):561-565.

4. FKG. BT-race biological and conservative. Switzerland: FKG; 2016. [cited 2016 Apr 20]. Available from: http://www.fkg.ch/ products/endodontics/root-canal-preparation.

5. FKG. I race quick, effective and safe. Switzerland: FKG; 2016. [cited 2016 Apr 20]. Available from: http://www.fkg.ch/ products/endodontics/root-canal-preparation.

6. Oliveira CA, Meurer MI, Pascoalato C, Silva SR. Cone-beam computed tomography analysis of the apical third of curved roots after mechanical preparation with different automated systems. Braz Dent J 2009;20(5):376-381. 
7. López FU, Fachin EV, Camargo Fontanella VR, Barletta FB, Só MV, Grecca FS. Apical transportation: a comparative evaluation of three root canal instrumentation techniques with three different apical diameters. J Endod 2008 Dec;34(12): 1545-1548.

8. Paque F, Musch U, Hulsmann M. Comparison of root canal preparation using Race and ProTaper rotary Ni-Ti instruments. Int Endod J 2015 Jan;38(1):8-16.

9. Yamamura B, Cox TC, Heddaya B, Flake NM, Johnson JD, Paranjpe A. Comparing canal transportation and centering ability of endosequence and vortex rotary files by using microcomputed tomography. J Endod 2012 Aug;38(8):1121-1125.

10. Khalilak Z, Fallahdoost A, Dadresanfar B, Rezvani G. Comparison of extracted teeth and simulated resin blocks on apical canal transportation. Iran Endod J 2008 Fall;3(4): 109-112.

11. Debelian G, Trope M. BT-Race: biologic and conservative root canal instrumentation with the final restoration in mind. Endod Practice U S 2014 Feb;7(1):22-24.

12. Pasternak-Junior B, Sousa-Neto MD, Silva RG. Canal transportation and centering ability of RaCe rotary instruments. Int Endod J 2009 Jun;42(6):499-506.

13. Durack C, Patel S. Cone beam computed tomography in endodontics. Braz Dent J 2012;23(3):179-191.

14. Madani ZS, Goudarzipor D, Haddadi A, Saeidi A, Bijani A. A CBCT assessment of apical transportation in root canals prepared with hand K-flexofile and K3 rotary instruments. Iran Endod J 2014 Winter;10(1):44-48. 